(2) Open Access Full Text Article

\title{
Minocycline alleviates beta-amyloid protein and tau pathology via restraining neuroinflammation induced by diabetic metabolic disorder
}

This article was published in the following Dove Press journal:

Clinical Interventions in Aging

16 August 2013

Number of times this article has been viewed

\author{
Zhiyou Cai' \\ Yong Yan ${ }^{2}$ \\ Yonglong Wang ${ }^{2}$ \\ 'Department of Neurology, the Lu'an \\ Affiliated Hospital of Anhui Medical \\ University, Lu'an People's Hospital, \\ Lu'an, Anhui Province, People's \\ Republic of China; ${ }^{2}$ Department \\ of Neurology, the First Affiliated \\ Hospital of Chongqing Medical \\ University, Chongqing Key Laboratory \\ of Neurology, Chongqing, People's \\ Republic of China
}

Background: Compelling evidence has shown that diabetic metabolic disorder plays a critical role in the pathogenesis of Alzheimer's disease, including increased expression of $\beta$-amyloid protein $(A \beta)$ and tau protein. Evidence has supported that minocycline, a tetracycline derivative, protects against neuroinflammation induced by neurodegenerative disorders or cerebral ischemia. This study has evaluated minocycline influence on expression of $A \beta$ protein, tau phosphorylation, and inflammatory cytokines (interleukin- $1 \beta$ and tumor necrosis factor- $\alpha$ ) in the brain of diabetic rats to clarify neuroprotection by minocycline under diabetic metabolic disorder.

Method: An animal model of diabetes was established by high fat diet and intraperitoneal injection of streptozocin. In this study, we investigated the effect of minocycline on expression of A $\beta$ protein, tau phosphorylation, and inflammatory cytokines (interleukin- $1 \beta$ and tumor necrosis factor- $\alpha$ ) in the hippocampus of diabetic rats via immunohistochemistry, western blotting, and enzyme-linked immunosorbent assay.

Results: These results showed that minocycline decreased expression of $A \beta$ protein and lowered the phosphorylation of tau protein, and retarded the proinflammatory cytokines, but not amyloid precursor protein.

Conclusion: On the basis of the finding that minocycline had no influence on amyloid precursor protein and beta-site amyloid precursor protein cleaving enzyme 1 which determines the speed of $A \beta$ generation, the decreases in $A \beta$ production and tau hyperphosphorylation by minocycline are through inhibiting neuroinflammation, which contributes to $A \beta$ production and tau hyperphosphorylation. Minocycline may also lower the self-perpetuating cycle between neuroinflammation and the pathogenesis of tau and $A \beta$ to act as a neuroprotector. Therefore, the ability of minocycline to modulate inflammatory reactions may be of great importance in the selection of neuroprotective agents, especially in chronic conditions like diabetes and Alzheimer's disease.

Keywords: diabetes mellitus, minocycline, tau protein, $\beta$-amyloid protein

\section{Introduction}

Alzheimer's disease (AD) is a neurodegenerative disorder that is characterized by progressive cognitive impairment. Histopathological hallmarks mainly indicate extracellular amyloid peptide deposition in neuritic plaques and intracellular deposits of hyperphosphorylated tau. Glucose metabolic disorders are probably an initiating factor. ${ }^{1,2} \mathrm{~A}$ variety of mechanisms have been postulated in the risk of $\mathrm{AD}$ and diabetes mellitus (DM). ${ }^{3,4}$ Some scholars have even proposed that AD is type 3 diabetes. ${ }^{5,6}$ However, the relationship between DM and the process of AD remains elusive.
Correspondence: Zhiyou Cai Department of Neurology, the Lu'an Affiliated Hospital of Anhui Medical University, Lu'an People's Hospital No 21 Wanxi West Road, Lu'an, Anhui Province, People's Republic of China, 237005

Tel +865643338520

Fax +865643338520

Email c0909@hotmail.com 
Minocycline, a tetracycline derivative, has a neuroprotective capability by limiting inflammation and oxidative stress. ${ }^{7,8}$ Previously, we have found that minocycline can downregulate $\beta$-amyloid protein $(A \beta)$ in the hippocampus, caused by diabetic metabolic disorder through inhibition of nuclear factor- $\kappa \mathrm{B}$ pathway activation. ${ }^{9}$ In addition, several studies from our group have also evidenced that minocycline improves cognitive impairment triggered by both cerebral ischemia and diabetic metabolic disorder. ${ }^{9-11}$ It is well accepted that the neuroinflammation induced by diabetic disorder plays an important role in $\mathrm{A} \beta$ production and the hyperphosphorylation of tau. ${ }^{12,13}$ To further evaluate the neuroprotective role of minocycline in the diabetes related neurodegenerative process of $\mathrm{AD}$, the present study was implemented to detect levels of tau and $A \beta$ proteins in the brain of a DM model established by high fat diet and intraperitoneal injection of streptozocin (STZ), and observe the effects of minocycline on the inflammatory markers and levels of tau and $A \beta$ proteins. These results noted that minocycline decreased the levels of the inflammatory markers and $\mathrm{A} \beta$, and inhibited the hyperphosphorylation of tau in the hippocampus of rats with DM. This study suggests that minocycline can reduce neuroinflammation, and then lowers the hyperphosphorylation of tau and the level of expression of $A \beta$.

\section{Methods}

\section{Animals and minocycline administration}

Thirty-six Sprague-Dawley rats (10-month-old, female, body weight 200-250 g from the Third Military Medical University for Animal Field Hospital, Chongqing, People's Republic of China) were fed with high fat and high sugar for 2 months (food composition: 10\% lard, 20\% sucrose, 2.5\% cholesterol, bile salt $1 \%, 6.5 \%$ conventional food) to induce the onset of insulin resistance, ${ }^{14}$ and the diabetes model was established by $50 \mathrm{mg} / \mathrm{kg}$ intraperitoneal injection of streptozocin (STZ) (Sigma Chemical Co, St Louis, MO, USA) after the 2 month high fat and high sugar feed. ${ }^{9,15}$ Animals were randomly divided into a control model group (subdivided into 4, 6, and 8 weeks after establishment of diabetes, with 6 animals per subgroup) and a minocycline intervention group (subdivided into 4,6 , and 8 weeks after minocycline intervention, respectively, with 6 animals per subgroup). Minocycline was administered by gavage on the same days as the STZ injection. The investigation conformed to the Guide for the Care and Use of Laboratory Animals published by the US National Institutes of Health (NIH Publication No 85-23, revised 1996). ${ }^{16}$ The animal experiments were performed according to internationally followed ethical standards and approved by the research ethics committee of Chongqing Medical University, Chongqing, People's Republic of China.

Minocycline (100 mg/capsule, made by China Huishi Pharmaceutical Limited Company, People's Republic of China) was dissolved into $0.5 \mathrm{mg} / \mathrm{mL}$ density with saline. The animals in the minocycline intervention group were executed through gavage via the stomach by $50 \mathrm{mg} / \mathrm{kg} /$ day of minocycline. Diabetic rats were administered the same volume of buffer by douche via the stomach. The minocycline dosage was determined according to the previous studies. ${ }^{9,17}$ Minocycline was administered by gavage 2 days after STZ injection.

\section{Enzyme-linked immunosorbent assay (ELISA)}

A $500 \mathrm{pg} / \mathrm{mL}$ solution was prepared as manufacturer's instruction and a standard curve created using computer software (Microsoft Excel [version 2010], Microsoft, Redmond, Washington, USA) capable of generating a four parameter logistic curve fit. Rat hippocampus tissues were dissected and homogenized in tissue protein extraction reagent buffer (Biosource International, Inc, Camarillo, CA, USA). The analysis of $A \beta$ by ELISA was conducted. $A \beta$ inhibitors and 4-benzenesulfonyl fluoride hydrochloride (Sigma Chemical $\mathrm{Co}$,) were added to tissue lysates to prevent degradation of $A \beta$. The concentration of $A \beta_{40 / 42}$ was measured using the $A \beta_{40}$ or $\mathrm{A} \beta_{42}$ Colorimetric ELISA kit (Biosource International, Inc) according to the manufacturer's instruction.

\section{Western blotting}

Samples were collected in the presence of protease inhibitors. After homogenization, the lysates were centrifuged at $100,000 \times \mathrm{g}$, and the supernatants were saved for western blot. Equal amounts of lysates were subject to sodium dodecyl sulfate polyacrylamide gel electrophoresis (Tris-glycine mini gel; 1:2500; Biosource International, Inc) and western blot analysis using antibodies specific for the following: interleukin (IL)-1 $\beta$, tumor necrosis factor (TNF)- $\alpha, \mathrm{A} \beta$ precursor protein (APP), and tau proteins. The optical densities of the specific bands were measured by image analysis software (HPIAS 2000, Tongji Qianping Company, Wuhan, People's Republic of China).

\section{Immunohistochemical assay}

Avidin-Biotin Complex (ABC) method is a standard IHC method and a widely used technique for immunhistochemical staining. Avidin, a large glycoprotein, can be labeled with peroxidase or fluorescein and has a very high affinity for biotin. Biotin, a low molecular weight vitamin, can 
be conjugated to a variety of biological molecules such as antibodies. The second antibody, a goat anti-mouse immunoglobulin (Ig) labeled with biotin, was from Vector Laboratories, Burlingame CA, USA. The intensity of staining for each of two hundred cells was adjusted. Five grades distinguished the degrees of staining, which represented five reaction coefficients, respectively. The five products of every coefficient and the corresponding cell number were added up, which resulted in the value of a positive score. All slides were measured in duplicate. Those samples with a score over 10 , or frequency over $5 \%$, were considered as positive.

\section{Statistical analysis}

All statistical data were analyzed via the SPSS software for Windows 2000 (SPSS, Inc, Chicago, IL, USA). One-way analysis of variance was employed. A standard curve was used for analysis of ELISA results. $P<0.05$ was considered as statistically significant.

\section{Results}

\section{Minocycline decreased expression of $A \beta$ but not APP}

The ELISA results showed that the $A \beta_{40}$ levels were significantly decreased from $56.43 \pm 7.03 \mathrm{pg} / \mathrm{mg}$ in the model animals to $26.03 \pm 6.13 \mathrm{pg} / \mathrm{mg}$ of lysate in the minocycline administration $(P=0.0001)$, and $\mathrm{A} \beta_{42}$ levels from $89.45 \pm 9.28 \mathrm{pg} / \mathrm{mg}$ to $39.04 \pm 6.03 \mathrm{pg} / \mathrm{mg}$ of lysates $(P=0.0003)$ (Figure 1A). However, the results by immunostaining indicated that minocycline intervention had no effect on APP (Figure 1B).

\section{Minocycline decreased phosphorylation of tau}

The previous results showed that minocycline restrained expression of $A \beta$ that occurs in the central nervous system during abnormal glucose metabolism. To further explore the neuroprotective mechanism of minocycline in a diabetic state, total and phosphorylated tau proteins (a molecular marker of $\mathrm{AD}$ ) were tested by western blotting or immunohistochemistry. The levels of total tau protein by western blotting or immunohistochemistry showed no significant change between control and the minocycline intervention group (Figure 2A). The levels of phosphorylated tau proteins, including pre-tangle marker phospho-tau antibody TG3 (pT231), intraneuronal tangle marker phospho-tau protein (Ser214, pS214), and extracellular tangle marker PHD finger protein-1 ([PHF-1] pS396/pS404), significantly decreased

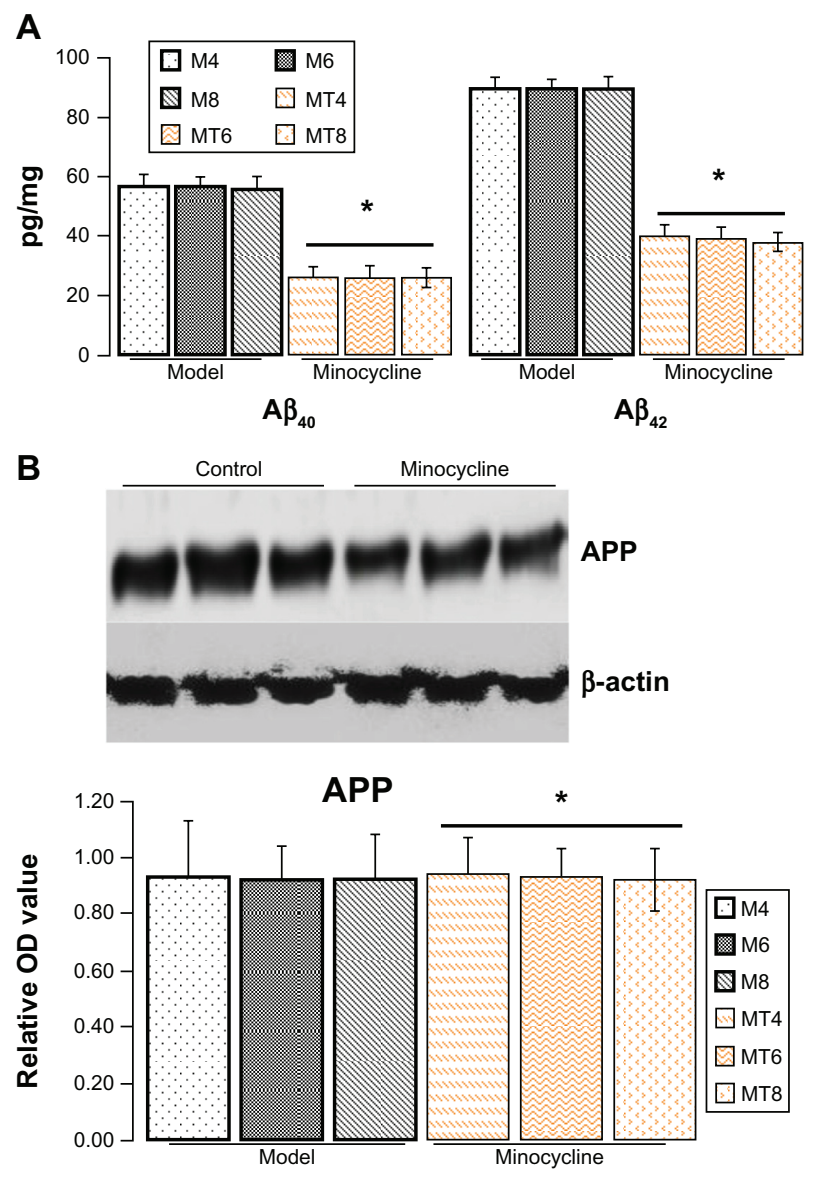

Figure I Assay of $A \beta_{40 / 42}$ and amyloid precursor protein.

Notes: (A) The levels of $A \beta_{40 / 42}$ proteins were measured by ELISA according to the manufacturer's instruction. The expression of $A \beta_{40 / 42}$ protein in the minocycline treatment group was significantly decreased when compared with the control model group. *Denotes $P<0.01$ versus control group. (B) The levels of amyloid precursor protein were measured by immunostaining ( $1: 200$, Biosource International, Inc, Camarillo, CA, USA). It seems that there is no significant difference between the control model group and the minocycline intervention group. *Denotes $P>0.05$ versus control group. The model group was subdivided into M4, M6, and M8 for 4,6 , and 8 weeks after streptozocin injection, and the minocycline administration group into MT4, MT6, and MT8.

Abbreviations: APP, amyloid precursor protein; M4, M6, M8: 4, 6, and 8 weeks after establishment of diabetes; MT4, MT6, MT8: 4, 6, and 8 weeks after minocycline intervention; OD, optical density.

after minocycline treatment $(P=0.0001)$, when compared with control model animals (Figure 2B).

\section{Minocycline downregulated IL-I $\beta$ and TNF- $\alpha$}

Increasing research studies have supported that diabetes induced neuroinflammation plays a crucial role in tau and $\mathrm{A} \beta$ pathogenesis. ${ }^{12,18,19}$ Whether such neuroprotective effects of minocycline on diabetic metabolism disorder are through inhibiting inflammation is still unclear. To clarify the academic hypothesis, the proinflammatory cytokines, IL- $1 \beta$ and TNF- $\alpha$, were detected here by ELISA and western blotting. The results by ELISA showed that IL- $1 \beta$ levels significantly 

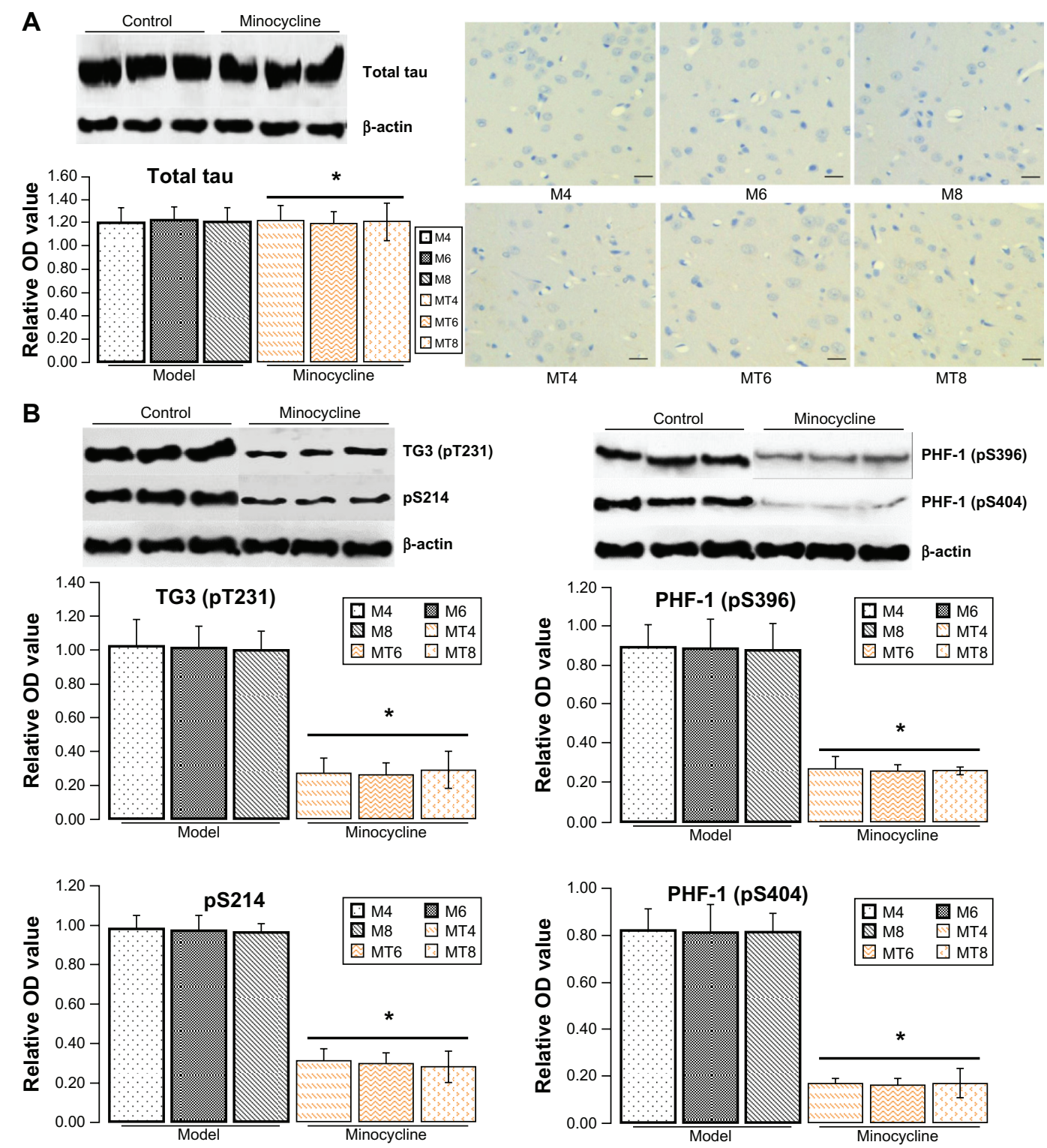

Figure 2 Assay for tau proteins.

Notes: (A) The levels of total tau protein (Bioss Co, Beijing, People's Republic of China) by western blotting (I:200) or immunohistochemistry (I:I00) showed no significant change between the control and minocycline intervention group. *Denotes $P>0.05$ versus control group. (B) The levels of phosphorylated tau proteins by western blotting as expressed by the densitometry ratio of tau proteins to $\beta$-actin (mean \pm standard deviation) were measured, including pre-tangle marker phospho-tau antibody TG3 (pT23I), intraneuronal tangle marker phospho-tau protein (Ser2I4, pS2 14), and extracellular tangle marker PHD finger protein-I (pS396/pS404). These results showed that the optical density value of phospho-tau proteins significantly decreased after minocycline treatment $(P=0.0001)$. pT23I (I:200), pS2 I4 (I:200), pS396 (I:I00), and pS404 (I:100) were purchased from Bioss Co, Scale bar is $20 \mu \mathrm{m}$.

Abbreviations: OD, optical density; M4, M6, M8: 4, 6, and 8 weeks after establishment of diabetes; MT4, MT6, MT8: 4, 6, and 8 weeks after minocycline intervention; PHF-I, PHD finger protein-I.

decreased from $56.32 \pm 6.02 \mathrm{pg} / \mathrm{mg}$ in control model animals to $25.48 \pm 6.35 \mathrm{pg} / \mathrm{mg}$ of lysates in the minocycline treatment group $(P=0.0005)$, while TNF- $\alpha$ levels were reduced from $42.43 \pm 6.62 \mathrm{pg} / \mathrm{mg}$ in control model animals to $23.44 \pm 6.52$ $\mathrm{pg} / \mathrm{mg}$ in the minocycline treated animals $(P=0.0001)$ (Figure 3A). Similar to the previous ELISA results, the levels of IL- $1 \beta$ and TNF- $\alpha$, as measured by western blotting, were distinctly lower after minocycline treatment $(P=0.0001)$ when compared with control model animals (Figure 3B).

\section{Discussion}

STZ, a powerful alkylating agent used to develop animal models to study diabetes and associated complications, is particularly toxic to the insulin-producing beta cells of the pancreas in mammals via interfering with glucose transport and impacting glucokinase function. Diabetic models will be successfully established, which occurred with cataract, hyperglycemia, uric acid, diabetic nephropathy, and a blood glucose level equal to or above $150 \mathrm{mg} / \mathrm{dL}$ were identified 
A
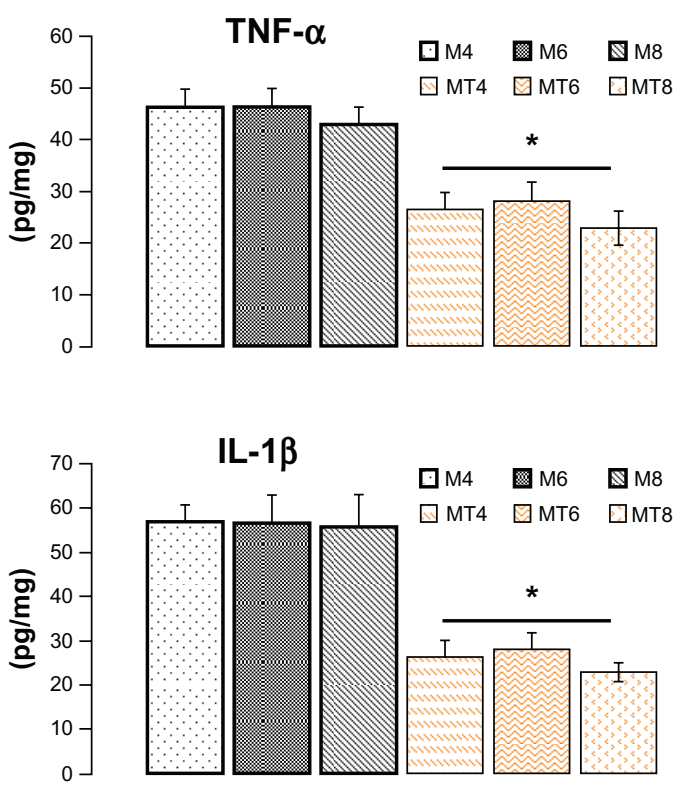

B
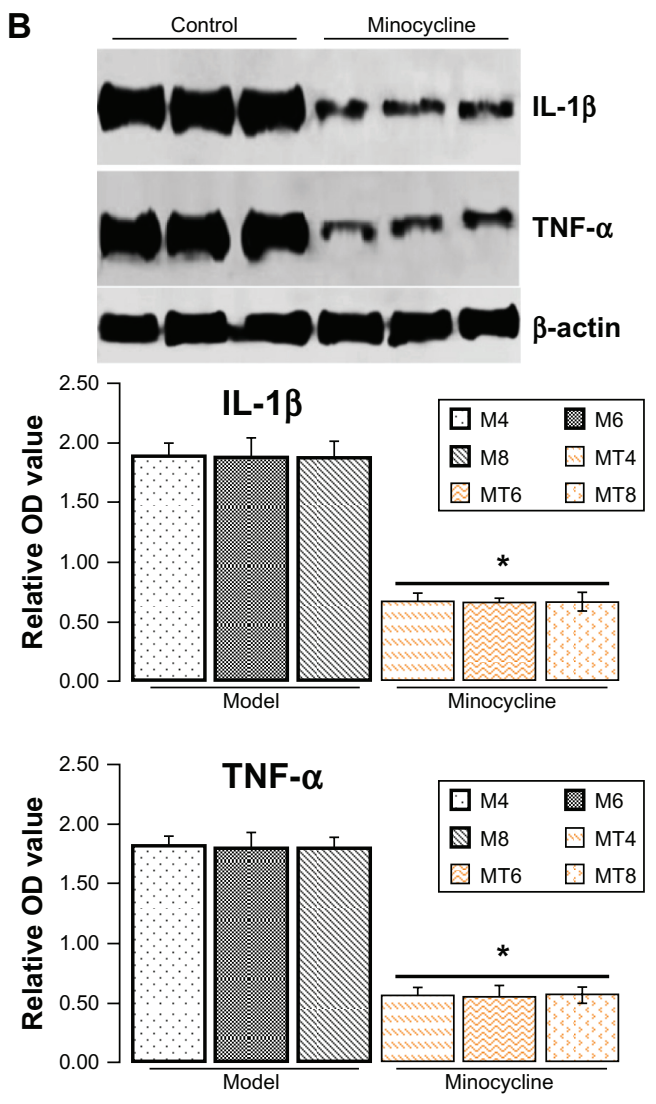

Figure 3 Assay of protein level of interleukin- $I \beta$ and tumor necrosis factor- $\alpha$.

Notes: (A) The levels of interleukin (IL)-I $\beta$ and tumor necrosis factor (TNF)- $\alpha$ by enzyme-linked immunosorbent assay in the minocycline treatment group decreased more significantly than in the control model group. *Denotes $P<0.00$ I. (B) The levels of IL-I $\beta$ and TNF- $\alpha$ by western blotting, as expressed by the densitometry ratio of IL-I $\beta$ and TNF- $\alpha$ to $\beta$-actin (mean \pm standard deviation), was more evidently reduced in the minocycline treatment group than in the control model group. $*$ Denotes $P<0.01$ versus control model group.

Abbreviations: IL-I $\beta$, interleukin-I $\beta$; OD, optical density; TNF- $\alpha$, tumor necrosis factor- $\alpha$; M4, M6, M8: 4, 6, and 8 weeks after establishment of diabetes; MT4, MT6, MT8: 4, 6, and 8 weeks after minocycline intervention.

as diabetic while the blood glucose level of normal rats varied between 50 to $135 \mathrm{mg} / \mathrm{dL} .^{18,19}$ Diabetic animals were continually given a high fat and high sugar diet. This study demonstrated that minocycline inhibited tau phosphorylation and decreased $A \beta$ protein to maintain neural function, and attenuated neuroinflammation under diabetic metabolism disorder, indicating the neuroprotective role of minocycline in $\mathrm{AD}$ via inhibiting neuroinflammation.

Minocycline, an antibiotic that effectively crosses the blood-brain barrier, has been found to have significant neuroprotective effects on cerebral ischemia disorders,${ }^{20,21}$ demyelinating diseases, ${ }^{22,23}$ and especially in neurodegenerative disorders including amyotrophic lateral sclerosis, ${ }^{24,25}$ $\mathrm{AD},{ }^{26}$ Huntington's disease, ${ }^{27,28}$ and Parkinson's disease.${ }^{26,29}$ Previously, the results from our group have demonstrated that minocycline improved cognitive impairment and retarded $\mathrm{A} \beta$ generation in the hippocampus caused by diabetic metabolic disorder, through inactivating the nuclear factor- $\kappa \mathrm{B}$ pathway. ${ }^{9}$ Considering the critical role of tau and $A \beta$ pathology in the progress of cognitive impairment, ${ }^{30,31}$ it is possible that minocycline improves cognitive impairment via limiting tau hyperphosphorylation and $A \beta$ pathology. On the basis of the finding that minocycline had no influence on beta-site amyloid precursor protein cleaving enzyme 1 in diabetic disorder, which determines the speed of A $\beta$ generation, ${ }^{9}$ it seems that minocycline has no modification on APP, since the critical role in $\mathrm{A} \beta$ generation is through modulating APP processing, and minocycline has no influence on APP level in this study.

Literature has shown that the two classical histopathological hallmarks include amyloid plaques (extracellular A $\beta$ deposition) and neurofibrillary tangles (intracellular deposits of hyperphosphorylated tau protein) in AD. ${ }^{32-35}$ The hyperphosphorylation of tau plays an important role in the progress of AD. This study detected the levels of phosphorylated tau proteins, including pre-tangle marker phospho-tau antibody TG3 (pT231), ${ }^{34,35}$ intraneuronal tangle marker phospho-tau protein (Ser214, pS214), and the extracellular tangle marker 
PHF-1 (pS396/pS404). ${ }^{36,37}$ The results from this research found that minocycline strongly limited the phosphorylation of tau protein, including TG3 (pT231), pS214, and PHF-1 (pS396/pS404), but not total tau. These data implicate that one of the neuroprotective roles of minocycline is via the suppression of the tau phosphorylation.

A variety of research data supports that minocycline acts as the neuroprotector via inhibiting brain inflammation, ${ }^{9,10}$ astrocyte reactivation, ${ }^{38}$ microglia activation, ${ }^{39-41}$ oxidative stress, ${ }^{9,38}$ apoptosis, ${ }^{9}$ and extracellular matrix degradation. ${ }^{42}$ Two common pathophysiological mechanisms of diabetic damage include oxidative stress and inflammation. Increasing evidence suggests that TNF- $\alpha$ and IL- $1 \beta$ (the inflammation markers) participate in the progression of brain injury from diabetes. ${ }^{43,44}$ To further explain the neuroprotective mechanisms of minocycline, TNF- $\alpha$ and IL-1 $\beta$ were measured. The decrease of TNF- $\alpha$ and IL- $1 \beta$ evoked by minocycline occurred in this investigation. Accordingly, minocycline decreased tau hyperphosphorylation and downregulated $\mathrm{A} \beta$ protein by restraining neuroinflammation from diabetes, while inflammation contributes to both the hyperphosphorylation of tau and $A \beta$ generation.

Neuroinflammation may be responsible for neurodegeneration in vulnerable regions such as the hippocampus. ${ }^{45,46}$ There is growing evidence that supports a prominent role of inflammation in the development of AD. ${ }^{47}$ An important feature of $\mathrm{AD}$ is that the hyperphosphorylation of tau and $\mathrm{A} \beta$ deposit may trigger an active, self-perpetuating cycle of chronic neuroinflammation which serves to further promote the hyperphosphorylation of tau and $\mathrm{A} \beta$ generation. ${ }^{48,49}$ Therefore, minocycline may lower the self-perpetuating cycle in the pathogenetic cascade of neurodegeneration in $\mathrm{AD}$, indicating that minocycline aims at both mechanisms to be a beneficial agent in the prevention and treatment of AD.

This study has evaluated the influence of minocycline on tau protein and $A \beta$ protein under diabetic disorder. Minocycline decreases the hyperphosphorylation of tau and $A \beta$ production by inhibiting the process of neuroinflammation. Minocycline may also lower the selfperpetuating cycle between neuroinflammation and the pathogenesis of tau and $A \beta$ to act as a neuroprotector, maintain neural function, and improve behavioral deficits under diabetic disorder. Accordingly, the ability of minocycline to modulate the inflammatory reaction may be of great importance in the selection of neuroprotective agents, especially in chronic procedures like AD. Hence, further studies exploring the effect of minocycline on these mechanisms may lead to better understanding and improvement of the role of treatment.

\section{Acknowledgments}

This study was supported in part by the Animal Center of Chongqing Medical University and research projects from the Ministry of Civil Affairs, People's Republic of China (2008-47-3-02).

\section{Disclosure}

The authors report no conflicts of interest in this work.

\section{References}

1. Wang KC, Woung LC, Tsai MT, Liu CC, Su YH, Li CY. Risk of Alzheimer's disease in relation to diabetes: a population-based cohort study. Neuroepidemiology. 2012;38:237-244.

2. Takeda S. [Pathological interaction between diabetes mellitus and Alzheimer's disease.] Nihon Shinkei Seishin Yakurigaku Zasshi. 2012;32:239-244. Japanese.

3. Kim B, Backus C, Oh S, Feldman EL. hyperglycemia-induced tau cleavage in vitro and in vivo: a possible link between diabetes and Alzheimer's disease. J Alzheimers Dis. 2013;34:727-739.

4. Bartl J, Monoranu CM, Wagner AK, Kolter J, Riederer P, Grunblatt E. Alzheimer's disease and type 2 diabetes: two diseases, one common link? World J Biol Psychiatry. 2013;14:233-240.

5. Pilcher H. Alzheimer's disease could be "type 3 diabetes". Lancet Neurol. 2006;5:388-389.

6. de la Monte SM, Tong M, Lester-Coll N, Plater M Jr, Wands JR. Therapeutic rescue of neurodegeneration in experimental type 3 diabetes: relevance to Alzheimer's disease. J Alzheimers Dis. 2006;10:89-109.

7. Zhang ZY, Zhang Z, Fauser U, Schluesener HJ. Improved outcome of EAN, an animal model of GBS, through amelioration of peripheral and central inflammation by minocycline. J Cell Mol Med. 2009;13: 341-351.

8. Kuang X, Scofield VL, Yan M, Stoica G, Liu N, Wong PK. Attenuation of oxidative stress, inflammation and apoptosis by minocycline prevents retrovirus-induced neurodegeneration in mice. Brain Res. 2009;1286: 174-184.

9. Cai Z, Zhao Y, Yao S, Bin Zhao B. Increases in beta-amyloid protein in the hippocampus caused by diabetic metabolic disorder are blocked by minocycline through inhibition of NF-kappaB pathway activation. Pharmacol Rep. 2011;63:381-391.

10. Cai ZY, Yan Y, Chen R. Minocycline reduces astrocytic reactivation and neuroinflammation in the hippocampus of a vascular cognitive impairment rat model. Neurosci Bull. 2010;26:28-36.

11. Cai ZY, Yan Y, Sun SQ, et al. Minocycline attenuates cognitive impairment and restrains oxidative stress in the hippocampus of rats with chronic cerebral hypoperfusion. Neurosci Bull. 2008;24:305-313.

12. Granic I, Dolga AM, Nijholt IM, van Dijk G, Eisel UL. Inflammation and NF-kappaB in Alzheimer's disease and diabetes. J Alzheimers Dis. 2009;16:809-821.

13. de la Monte SM. Brain insulin resistance and deficiency as therapeutic targets in Alzheimer's disease. Curr Alzheimer Res. 2012;9:35-66.

14. Dong SF, Hong Y, Liu M, et al. Berberine attenuates cardiac dysfunction in hyperglycemic and hypercholesterolemic rats. Eur J Pharmacol. 2011;660:368-374.

15. Reed MJ, Meszaros K, Entes LJ, et al. A new rat model of type 2 diabetes: the fat-fed, streptozotocin-treated rat. Metabolism. 2000;49: 1390-1394.

16. Clark JD, Gebhart GF, Gonder JC, Keeling ME, Kohn DF: Special Report: The 1996 Guide for the Care and Use of Laboratory Animals. ILAR J. 1997;38(1):41-48. 
17. Roulston CL, Lawrence AJ, Widdop RE, Jarrott B. Minocycline treatment attenuates microglia activation and non-angiotensin II [125I] CGP42112 binding in brainstem following nodose ganglionectomy. Neuroscience. 2005;135:1241-1253.

18. Ozaki K, Sano T, Tsuji N, Matsuura T, Narama I. Insulin-induced hypoglycemic peripheral motor neuropathy in spontaneously diabetic WBN/Kob rats. Comp Med. 2010;60:282-287.

19. Tze WJ, Tai J, Wong FC, Davis HR. Studies with implantable artificial capillary units containing rat islets on diabetic dogs. Diabetologia. 1980;19:541-545.

20. Bhattacharya P, Pandey AK, Paul S. Minocycline and magnesium in combination may be a good therapeutic intervention for cerebral ischemia. Med Hypotheses. 2011;77:1129-1131.

21. Martin A, Boisgard R, Kassiou M, Dolle F, Tavitian B. Reduced PBR/ TSPO expression after minocycline treatment in a rat model of focal cerebral ischemia: a PET study using [(18)F]DPA-714. Mol Imaging Biol. 2011;13:10-15.

22. Chen X, Ma X, Jiang Y, Pi R, Liu Y, Ma L. The prospects of minocycline in multiple sclerosis. J Neuroimmunol. 2011;235:1-8.

23. Defaux A, Zurich MG, Honegger P, Monnet-Tschudi F. Minocycline promotes remyelination in aggregating rat brain cell cultures after interferon-gamma plus lipopolysaccharide-induced demyelination. Neuroscience. 2011;187:84-92.

24. Zhang W, Narayanan M, Friedlander RM. Additive neuroprotective effects of minocycline with creatine in a mouse model of ALS. Ann Neurol. 2003;53:267-270.

25. Gordon PH, Moore DH, Miller RG, et al. Efficacy of minocycline in patients with amyotrophic lateral sclerosis: a phase III randomised trial. Lancet Neurol. 2007;6:1045-1053.

26. Blum D, Chtarto A, Tenenbaum L, Brotchi J, Levivier M. Clinical potential of minocycline for neurodegenerative disorders. Neurobiol Dis. 2004; 17:359-366.

27. Bantubungi $\mathrm{K}$, Jacquard C, Greco A, et al. Minocycline in phenotypic models of Huntington's disease. Neurobiol Dis. 2005;18:206-217.

28. Yong VW, Wells J, Giuliani F, Casha S, Power C, Metz LM. The promise of minocycline in neurology. Lancet Neurol. 2004;3:744-751.

29. Du Y, Ma Z, Lin S, et al. Minocycline prevents nigrostriatal dopaminergic neurodegeneration in the MPTP model of Parkinson's disease. Proc Natl Acad Sci U S A. 2001;98:14669-14674.

30. Amlien IK, Fjell AM, Walhovd KB, et al. Mild cognitive impairment: cerebrospinal fluid tau biomarker pathologic levels and longitudinal changes in white matter integrity. Radiology. 2013;266:295-303.

31. Parnetti L, Chiasserini D, Eusebi P, et al. Performance of abeta1-40, abeta1-42, total tau, and phosphorylated tau as predictors of dementia in a cohort of patients with mild cognitive impairment. $J$ Alzheimers Dis. 2012;29:229-238.

32. Lomoio S, Scherini E, Necchi D. Beta-amyloid overload does not directly correlate with SAPK/JNK activation and tau protein phosphorylation in the cerebellar cortex of Ts65Dn mice. Brain Res. 2009;1297: 198-206.
33. Mohandas E, Rajmohan V, Raghunath B. Neurobiology of Alzheimer's disease. Indian J Psychiatry. 2009;51:55-61.

34. Papon MA, E1 Khoury NB, Marcouiller F, et al. Deregulation of protein phosphatase 2A and hyperphosphorylation of tau protein following onset of diabetes in NOD mice. Diabetes. 2013;62:609-617.

35. Wang Y, Cheng Z, Qin W, Jia J. Va197 Leu mutant presenilin-1 induces tau hyperphosphorylation and spatial memory deficit in mice and the underlying mechanisms. J Neurochem. 2012;121:135-145.

36. Augustinack JC, Schneider A, Mandelkow EM, Hyman BT. Specific tau phosphorylation sites correlate with severity of neuronal cytopathology in Alzheimer's disease. Acta Neuropathol. 2002;103:26-35.

37. Liu Y, Su Y, Wang J, et al. Rapamycin decreases tau phosphorylation at Ser214 through regulation of cAMP-dependent kinase. Neurochem Int. 2013;62:458-467.

38. Keller AF, Gravel M, Kriz J. Treatment with minocycline after disease onset alters astrocyte reactivity and increases microgliosis in SOD1 mutant mice. Exp Neurol. 2011;228:69-79.

39. Giuliani F, Hader W, Yong VW. Minocycline attenuates T cell and microglia activity to impair cytokine production in $\mathrm{T}$ cell-microglia interaction. J Leukoc Biol. 2005;78:135-143.

40. Si Q, Cosenza M, Kim MO, et al. A novel action of minocycline: inhibition of human immunodeficiency virus type 1 infection in microglia. J Neurovirol. 2004;10:284-292.

41. Tikka T, Fiebich BL, Goldsteins G, Keinanen R, Koistinaho J. Minocycline, a tetracycline derivative, is neuroprotective against excitotoxicity by inhibiting activation and proliferation of microglia. J Neurosci. 2001;21:2580-2588.

42. Yenari MA, Xu L, Tang XN, Qiao Y, Giffard RG. Microglia potentiate damage to blood-brain barrier constituents: improvement by minocycline in vivo and in vitro. Stroke. 2006;37:1087-1093.

43. Parthsarathy V, Holscher C. The type 2 diabetes drug liraglutide reduces chronic inflammation induced by irradiation in the mouse brain. Eur $J$ Pharmacol. 2013;700:42-50.

44. Celik S, Erdogan S. Caffeic acid phenethyl ester (CAPE) protects brain against oxidative stress and inflammation induced by diabetes in rats. Mol Cell Biochem. 2008;312:39-46.

45. Hurley LL, Tizabi Y. Neuroinflammation, neurodegeneration, and depression. Neurotox Res. 2013;23:131-144.

46. Pintado C, Gavilan MP, Gavilan E, et al. Lipopolysaccharide-induced neuroinflammation leads to the accumulation of ubiquitinated proteins and increases susceptibility to neurodegeneration induced by proteasome inhibition in rat hippocampus. J Neuroinflammation. 2012;9:87.

47. Craft JM, Watterson DM, Van Eldik LJ. Human amyloid beta-induced neuroinflammation is an early event in neurodegeneration. Glia. 2006;53:484-490.

48. Cai Z, Zhao B, Ratka A. Oxidative stress and beta-amyloid protein in Alzheimer's disease. Neuromolecular Med. 2011;13:223-250.

49. Texel SJ, Mattson MP. Impaired adaptive cellular responses to oxidative stress and the pathogenesis of Alzheimer's disease. Antioxid Redox Signal. 2011;14:1519-1534.
Clinical Interventions in Aging

\section{Publish your work in this journal}

Clinical Interventions in Aging is an international, peer-reviewed journal focusing on evidence-based reports on the value or lack thereof of treatments intended to prevent or delay the onset of maladaptive correlates of aging in human beings. This journal is indexed on PubMed Central, MedLine, the American Chemical Society's 'Chemical Abstracts

\section{Dovepress}

Service' (CAS), Scopus and the Elsevier Bibliographic databases. The manuscript management system is completely online and includes a very quick and fair peer-review system, which is all easy to use. Visi http://www.dovepress.com/testimonials.php to read real quotes from published authors. 